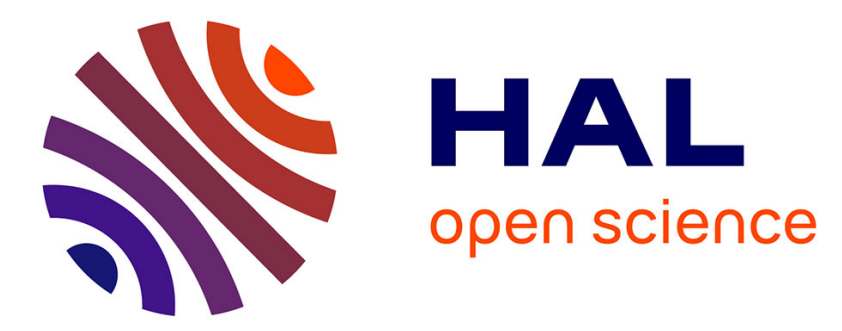

\title{
A Hybrid Soft Computing Approach Producing Robust Forest Fire Risk Indices
}

Vardis-Dimitris Anezakis, Konstantinos Demertzis, Lazaros Iliadis, Stefanos Spartalis

\section{- To cite this version:}

Vardis-Dimitris Anezakis, Konstantinos Demertzis, Lazaros Iliadis, Stefanos Spartalis. A Hybrid Soft Computing Approach Producing Robust Forest Fire Risk Indices. 12th IFIP International Conference on Artificial Intelligence Applications and Innovations (AIAI), Sep 2016, Thessaloniki, Greece. pp.191203, 10.1007/978-3-319-44944-9_17 . hal-01557607

\section{HAL Id: hal-01557607 https://hal.inria.fr/hal-01557607}

Submitted on 6 Jul 2017

HAL is a multi-disciplinary open access archive for the deposit and dissemination of scientific research documents, whether they are published or not. The documents may come from teaching and research institutions in France or abroad, or from public or private research centers.
L'archive ouverte pluridisciplinaire HAL, est destinée au dépôt et à la diffusion de documents scientifiques de niveau recherche, publiés ou non, émanant des établissements d'enseignement et de recherche français ou étrangers, des laboratoires publics ou privés. 


\title{
A Hybrid Soft Computing Approach Producing Robust Forest Fire Risk Indices
}

\author{
Vardis-Dimitris Anezakis ${ }^{1}$, Konstantinos Demertzis ${ }^{2}$, Lazaros Iliadis ${ }^{3}$, \\ Stefanos Spartalis ${ }^{4}$ \\ 1,2,3 Democritus University of Thrace, Lab of Forest-Environmental Informatics and \\ Computational Intelligence, 193 Pandazidou st., 68200 N Orestiada, Greece, \\ ${ }^{4}$ Democritus University of Thrace, Department of Production and Management Engineering, \\ Laboratory of Computational Mathematics, School of Engineering, V.Sofias 12, Prokat, \\ Building A1, 67100 Xanthi, Greece

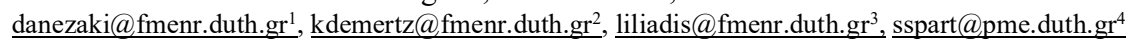

\begin{abstract}
Forest fires are one of the major natural disaster problems of the Mediterranean countries. Their prevention - effective fighting and especially the local prediction of the forest fire risk, requires the rational determination of the related factors and the development of a flexible system incorporating an intelligent inference mechanism. This is an enduring goal of the scientific community. This paper proposes an Intelligent Soft Computing Multivariable Analysis system (ISOCOMA) to determine effective wild fire risk indices. More specifically it involves a Takagi-Sugeno-Kang rule based fuzzy inference approach, that produces partial risk indices (PRI) per factor and per subject category. These PRI are unified by employing fuzzy conjunction TNorms in order to develop pairs of risk indices (PARI). Through Chi Squared hypothesis testing, plus classification of the PARI and forest fire burned areas (in three classes) it was determined which PARI are closely related to the actual burned areas. Actually we have managed to determine which pairs of risk indices are able to determine the actual burned area for each case under study. Wild fire data related to specific features of each area in Greece were considered. The Soft computing approach proposed herein, was applied for the cases of Chania, and Ilia areas in Southern Greece and for Kefalonia island in the Ionian Sea, for the temporal period 1984-2004.
\end{abstract}

Keywords: Takagi-Sugeno-Kang, Fuzzy Inference System, T-Norms, ChiSquare Test, Individual Indices, Unified Index, Forest Fires

\section{Introduction}

Greece has a very important forest capital, as $50 \%$ of the territory is covered by woodland. About $25 \%$ of it is characterized by high vegetation coniferous and broadleaf high biodiversity, the remaining of low trees and shrubs near inhabited areas. Also there are approximately 2 million acres of rangelands. During the last 20 years, the average annual burned areas in the country are higher than 45,000 acres as a result of 1500 forest fires. The determination of the factors that favor ignition and 
contribute to the spread of wild fires (WF) requires a detailed spatiotemporal analysis of the historical data for each area under study. Moreover, the specification of the correlations between these parameters is absolutely necessary. This research paper proposes an innovative hybrid forest fire modeling system operating on a local basis. The reasoning of the ISOCOMA employs Computational Intelligence approaches in order to produce an overall fire risk index.

\subsection{Literature review}

Iliadis and Betsidou [9] have implemented an intelligent rule based fuzzy inference system (FIS) evaluating wild fire risk for the forest departments of Greece. The estimation of the risk indices was done by using fuzzy triangular membership functions and Einstein fuzzy conjunction T-Norms. Iliadis and Zigkrika [11] have also developed a FIS that performs and evaluates scenarios (by assigning weights to the involved features) towards the estimation of a characteristic overall forest fire risk index in Greece. Papakonstantinou et al. [17] have proposed a fuzzy rule based system to produce the drought risk indices vectors for the forest regions of Cyprus under study. Iliadis et al. [10] have developed a fuzzy inference system under the MATLAB platform. The system uses three distinct Gaussian distribution fuzzy membership functions in order to estimate the partial and the overall risk indices due to wild fires in the southern part of Greece. Özbayoğlu and Bozer [16] estimated the potential burned areas using geographical and meteorological data. Several computational intelligence approaches were used namely: Multilayer Perceptron (MLP), Radial Basis Function Networks (RBFN), Support Vector Machines (SVM) and fuzzy logic. Shidik and Mustofa [18] used a Back-Propagation Neural Network which was trained based on meteorological and forest weather indices, so as to classify the burned area in three categories. Aldrich et al. [1] investigated the effect of variations in land use and climate in the occurrence of forest fires. Catry et al. [6] used logistic regression models to predict the relative probability of ignition occurrence, as a function of the resulting fire size.

\subsection{Innovations of the Proposed Methodology}

The main innovation of the ISICOMA is the development of four partial risk indices (PRI), which are derived from the respective analysis of separate parameters, creating and analyzing meaningful relationships and rules of correlations between them. This raises the problem of wild fires (WF) on an absolutely realistic basis. In addition, it is for the first time that an intelligent system combines the use of an adaptive fuzzy inference Takagi-Sugeno-Kang (AFITS) system with the wide use of fuzzy conjunction T-Norms in order to obtain higher fitting rates between PRI and TPRI with the actual burned areas. 


\subsection{Data}

The first step towards the development of an overall wild fire risk index model was the determination of all factors that affect the behavior of a forest fire. The data collected from the forest inspections and from the Hellenic national meteorological service. According to [12] the following factors have been identified as playing a key role.

Table 1. Factors affecting fire behavior

\begin{tabular}{cc}
\hline Flammability of vegetation & Monthly Rainfall \\
\hline Canopy Density & Previous Month Rainfall \\
Vegetation Density & Altitude \\
Air Temperature & Slope \\
Relative Humidity & Ground Orientation \\
Wind Speed & Exposure \\
Daily Rainfall & \\
\hline
\end{tabular}

Utilizing and analyzing in-depth studies in the raw meteorological, topographical and vegetative data of the areas concerned $[3,4]$ the following categories were obtained (Table 2).

Table 2. Classification of the fire parameters

\begin{tabular}{|c|c|c|c|c|c|c|c|}
\hline & Parameters & Class1 & Class2 & Class3 & Class4 & Class5 & Class6 \\
\hline \multirow[b]{2}{*}{ Meteorological } & Wind & $0-1 b f$ & $1.1-4 \mathrm{bf}$ & $4.1-7 \mathrm{bf}$ & $\begin{array}{l}7.1- \\
9 \mathrm{bf}\end{array}$ & $>9.1 \mathrm{bf}$ & \\
\hline & $\begin{array}{c}\text { Air } \\
\text { temperature } \\
\text { /Relative } \\
\text { Humidity }\end{array}$ & Low risk & $\begin{array}{l}\text { Medium } \\
\text { risk }\end{array}$ & $\begin{array}{l}\text { High } \\
\text { risk }\end{array}$ & & & \\
\hline \multirow{3}{*}{ Topographic } & Slope & $0-20 \%$ & $21-40 \%$ & $41-60 \%$ & $\begin{array}{c}61- \\
80 \%\end{array}$ & $\begin{array}{c}81- \\
100 \%\end{array}$ & $>100 \%$ \\
\hline & $\begin{array}{l}\text { Ground } \\
\text { Orientation } \\
\text { Exposure }\end{array}$ & Unspecified & North & South & East & West & \\
\hline & Altitude & Low & Medium & High & & & \\
\hline \multirow{3}{*}{ Vegetation } & $\begin{array}{l}\text { Canopy } \\
\text { Density }\end{array}$ & Absent & Rare & Full & & & \\
\hline & $\begin{array}{l}\text { Vegetation } \\
\text { Density }\end{array}$ & Absent & $\begin{array}{c}\text { Rare } \\
\text { Canopy }<0.4\end{array}$ & $\begin{array}{c}\text { Dense } \\
\text { Canopy } \\
>0.4\end{array}$ & & & \\
\hline & $\begin{array}{l}\text { Flammability } \\
\text { of vegetation }\end{array}$ & Low risk & $\begin{array}{l}\text { Medium } \\
\text { risk }\end{array}$ & $\begin{array}{l}\text { High } \\
\text { risk }\end{array}$ & & & \\
\hline Drought & $\begin{array}{l}\text { Rainfall } \\
\text { (Daily, } \\
\text { Monthly, } \\
\text { Previous } \\
\text { Month) }\end{array}$ & Low & Medium & High & & & \\
\hline
\end{tabular}

\subsection{Areas of Study}

Kefalonia (island in the Ionian Sea) Ilia (prefecture in Peloponnese) and Chania (prefecture in Crete island) have been chosen as the areas of interest. They have rich 
vegetation, they have protected areas (under Natura network) and their climate is dry and hot with low rain height. Also both Chania and Kefalonia are characterized by high touristic development and growth with high land value. On the other hand ancient Olympia is located in Ilia prefecture. Thus, it is an area of high cultural and touristic value. During the period 1984-2014, totally 1397 wild fires occurred in Ilia, 857 in Chania and 1298 in Kefalonia.

The Fire Ignition Indicator (FIGI) which emerges by combining the effect of temperature and humidity and the Spread Index which considers the effect of wind and slope (SPRI) have been used to produce significant evidence of forest fire risk. In a previous research effort of our team [2] have found that the SPRI is "High" in the $30-50 \%$ of the cases, whereas the FIGI has shown smaller high and medium hazard rates.

\section{Theoretical Framework and Methodology}

\subsection{Fuzzy Inference Systems}

The Sugeno Fuzzy implication is the basic modeling approach used by the ISOCOMA. Introduced in 1985 [19], it is similar to the Mamdani method. While Mamdani FIS uses the technique of defuzzification of a fuzzy output, Sugeno FIS uses weighted average to compute the crisp output. The fuzzy membership functions (FMF) of the output are either linear (first order polynomials or constant crisp values). A typical rule in a Sugeno fuzzy model if the outputs are first-order linear has the form:

If Input $1=x$ and Input $2=y$ then Output is $z=a x+$ by $+c$

For a zero-order Sugeno model, the output level $\mathrm{z}$ is a constant crisp value $\mathrm{c}(\mathrm{a}=\mathrm{b}=0)$. The output level $\mathrm{z}_{\mathrm{i}}$ of each rule is weighted by the firing strength $\mathrm{w}_{\mathrm{i}}$ of the rule. For an AND rule with Input $1=x$ and Input $2=y$, the firing strength is

$$
\mathrm{w}_{\mathrm{i}}=\text { AndMethod }\left(\mathrm{F}_{1}(\mathrm{x}), \mathrm{F}_{2}(\mathrm{y})\right)
$$

where $F_{1,2}$ are the membership functions for Inputs 1 and 2 . The final output of the system is the weighted average of all rule outputs, computed as in (3).

Final output $=\frac{\sum_{i=1}^{N} w_{i} z_{i}}{\sum_{i=1}^{N} w_{i}}$ where $\mathrm{N}$ is the number of rules

\subsection{T-Norms}

This paper attempts to calculate the Unique Overall Risk Index (UORI), resulting from the cumulative effect of all the related factors, after performing integration operations on all individual fuzzy sets. This task is carried out, by the use of specific fuzzy conjunction "AND" operators (CONO) known as T-Norms in the literature. The Min, the Algebraic, the Drastic, the Einstein and the Hamacher Products act as TNorms [5],[7],[13,14,15]. The T-Norms are the unifiers of partial risk indices and they are quite optimistic as they are assigning the minimum risk value to the overall index [8]. 


\subsection{Chi-Square Test}

The Chi-Squared hypothesis-testing is a non-parametric statistical test in which the sampling distribution of the test statistic is a chi-square distribution when the null hypothesis is true. The null hypothesis $\mathrm{H}_{0}$ usually refers to a general statement or default position that there is no relationship between two measured phenomena, or no difference among groups. The $\mathrm{H}_{0}$ is assumed to be true until evidence suggest otherwise [20]. The statistical control index used for this assessment is the test statistic $\mathrm{X}^{2}$.

$$
X^{2}=\sum \frac{\left(f_{o}-f_{e}\right)^{2}}{f_{e}}
$$

Where fe is the expected frequency and fo the observed one. The degrees of freedom are estimated as follows (based on the rXc table of labeled categories):

$$
d \mathrm{f}=(\mathrm{r}-1)(\mathrm{c}-1)
$$

For the $\mathrm{H}_{0}$ the critical values for the test statistic $\mathrm{X}^{2}$ are estimated by the $\mathrm{X}^{2}$ distribution after considering the degrees of freedom. If the result of the test statistic is less than the value of the Chi-Square distribution, then we accept $\mathrm{H}_{0}$ otherwise we reject it.

\section{Description of the proposed methodology}

The core of the modeling approach proposed herein was based on the grouping of twelve initial fire risk indices in four classes of partial risk indices and subsequently their integration into a unique overall one, the Conceptual Risk Index (CRI), for each fire incident and for each area of study. Then based on the burned area, the Actually Burned Surfaces Index (ACBUS) was determined. Moreover, we performed fuzzy conjunction (with T-Norms) of the four CRIi indices $(i=1 \ldots 4)$ selecting all combinations of pairs in order to find those that belong to the same Linguistics with the ones of ACBUS. For example, we tried to estimate the forest fire incidents that were assigned "High Risk" pairs of indices and at the same time "High Risk" ACBUS ones.

\subsection{The algorithm}

The proposed algorithmic process involves 9 distinct steps, which are discussed below:

1. Evaluating the twelve initial features influencing the phenomenon of forest fires and subsequently grouping them conceptually, in four thematic areas (feature categories). A distinct Conceptual Risk Index (CRI) has been developed for each feature category, totally four of them CRIi $(\mathrm{i}=1 . . .4)$. More specifically, the Weather Risk Index (WRI) was constructed from the contribution of temperature, humidity and wind speed. Correspondingly the drought index (DRI) comprises of the daily plus the monthly precipitation and of the precipitation in the previous month. The topographic Risk index (TRI) is related to the slope to the altitude and to the 
exposure. The vegetation Risk index (VRI) is defined by the flammability of forest species, the canopy density and the vegetation density. The same methodology has been followed for all three areas under study.

2. The Fuzzy Inference Engine Takagi-Sugeno-Kang (FIETS) has been used. According to it, each feature is fuzzified based on properly designed fuzzy Trapezoidal membership functions. In this way each parameter of each incident has been assigned fuzzy risk linguistics.

3. This process determines the corresponding fuzzy set (linguistic) for each wild fire incident.

4. Proper fuzzy weighted rule sets have been designed and implemented. The number of the trapezoidal fuzzy membership functions used for the determination of each partial risk index related to each one of the 12 parameters, was determined by the number of its corresponding classes in table 2 . The number of fuzzy sets created for each feature, were exactly as many as its corresponding classes in table 2. For the topographic parameter "Ground Orientation Exposure" the first class was removed because it was declared officially as unspecified.

Table 3. Fuzzy Sets and the corresponding Linguistics of each feature

\begin{tabular}{|c|c|c|c|c|c|}
\hline \multirow{2}{*}{\multicolumn{2}{|c|}{ Air temperature }} & Kefalonia & \multicolumn{2}{|c|}{ Chania } & Ilia \\
\hline & & $\begin{array}{c}3 \operatorname{Low}(\mathrm{L}), \operatorname{Medium}(\mathrm{M}), \\
\operatorname{High}(\mathrm{H})\end{array}$ & \multicolumn{2}{|c|}{$3 \mathrm{~L}, \mathrm{M}, \mathrm{H}$} & $3 \mathrm{~L}, \mathrm{M}, \mathrm{H}$ \\
\hline \multicolumn{2}{|c|}{ Relative Humidity, } & & \multicolumn{2}{|c|}{$3 \mathrm{~L}, \mathrm{M}, \mathrm{H}$} & $3 \mathrm{~L}, \mathrm{M}, \mathrm{H}$ \\
\hline \multicolumn{2}{|c|}{ Daily Rainfall } & $3 \mathrm{~L}, \mathrm{M}, \mathrm{H}$ & \multicolumn{2}{|c|}{$3 \mathrm{~L}, \mathrm{M}, \mathrm{H}$} & $3 \mathrm{~L}, \mathrm{M}, \mathrm{H}$ \\
\hline Mor & Rainfall & $2 \mathrm{M}, \mathrm{H}$ & \multicolumn{2}{|c|}{$3 \mathrm{~L}, \mathrm{M}, \mathrm{H}$} & $3 \mathrm{~L}, \mathrm{M}, \mathrm{H}$ \\
\hline \multicolumn{2}{|c|}{ Previous Month Rainfall } & $3 \mathrm{~L}, \mathrm{M}, \mathrm{H}$ & \multicolumn{2}{|c|}{$3 \mathrm{~L}, \mathrm{M}, \mathrm{H}$} & $3 \mathrm{~L}, \mathrm{M}, \mathrm{H}$ \\
\hline \multirow{2}{*}{\multicolumn{2}{|c|}{$\begin{array}{c}\text { Altitude } \\
\text { Flammability of vegetation }\end{array}$}} & \multirow{2}{*}{$\begin{array}{l}3 \mathrm{~L}, \mathrm{M}, \mathrm{H} \\
3 \mathrm{~L}, \mathrm{M}, \mathrm{H}\end{array}$} & \multicolumn{2}{|c|}{$3 \mathrm{~L}, \mathrm{M}, \mathrm{H}$} & $3 \mathrm{~L}, \mathrm{M}, \mathrm{H}$ \\
\hline & & & \multicolumn{2}{|c|}{$3 \mathrm{~L}, \mathrm{M}, \mathrm{H}$} & $3 \mathrm{~L}, \mathrm{M}, \mathrm{H}$ \\
\hline \multicolumn{2}{|c|}{$\begin{array}{l}\text { Canopy Density, Vegetation } \\
\text { Density }\end{array}$} & 3 Very Low(VL), L, H & \multicolumn{2}{|c|}{$3 \mathrm{VL}, \mathrm{L}, \mathrm{H}$} & $3 \mathrm{VL}, \mathrm{L}, \mathrm{H}$ \\
\hline \multicolumn{2}{|c|}{ Wind Speed } & $4 \mathrm{~L}, \mathrm{M}, \mathrm{H}$, Very High(VH) & \multicolumn{2}{|c|}{$\begin{array}{c}5 \mathrm{~L}, \mathrm{M}, \mathrm{H}, \mathrm{VH}, \mathrm{Ultra} \\
\mathrm{High}(\mathrm{UH})\end{array}$} & $\begin{array}{c}5 \mathrm{~L}, \mathrm{M}, \mathrm{H}, \mathrm{VH}, \\
\mathrm{UH}\end{array}$ \\
\hline & & $5 \mathrm{VL}, \mathrm{L}, \mathrm{M}, \mathrm{H}, \mathrm{VH}$, & \multicolumn{2}{|c|}{$\begin{array}{c}6 \mathrm{VL}, \mathrm{L}, \mathrm{M}, \mathrm{H}, \mathrm{VH} \\
\mathrm{UH}\end{array}$} & $\begin{array}{l}6 \mathrm{VL}, \mathrm{L}, \mathrm{M}, \mathrm{H} \\
\mathrm{VH}, \mathrm{UH}\end{array}$ \\
\hline \multicolumn{2}{|c|}{$\begin{array}{c}\text { Ground } \\
\text { Orientation Exposure }\end{array}$} & $4 \mathrm{VL}, \mathrm{L}, \mathrm{M}, \mathrm{H}$ & \multicolumn{2}{|c|}{$4 \mathrm{VL}, \mathrm{L}, \mathrm{M}, \mathrm{H}$} & $4 \mathrm{VL}, \mathrm{L}, \mathrm{M}, \mathrm{H}$ \\
\hline & \multicolumn{5}{|c|}{ able 4. Conceptual Fuzzy Sets and the Linguistics of the (CRI) } \\
\hline \multirow{2}{*}{ Kefalonia } & $\frac{61}{5}$ & $\frac{2 \pi}{3}$ & $1 \mathrm{MI}$ & $\sqrt{\mathrm{V}}$ & עता \\
\hline & $\mathrm{L}, \mathrm{M}, \mathrm{H}, \mathrm{VH}, \mathrm{U}$ & $\mathrm{L}, \mathrm{M}, \mathrm{H}$ & $\mathrm{L}, \mathrm{M}, \mathrm{H}, \mathrm{VH}$ & $\mathrm{L}, \mathrm{M}, \mathrm{H}, \mathrm{VH}$ & $\mathrm{L}, \mathrm{M}, \mathrm{H}, \mathrm{VH}, \mathrm{UH}$ \\
\hline \multirow[t]{2}{*}{ Chania } & 5 & 3 & 4 & 4 & 5 \\
\hline & $\mathrm{L}, \mathrm{M}, \mathrm{H}, \mathrm{VH}, \mathrm{U}$ & $\mathrm{L}, \mathrm{M}, \mathrm{H}$ & $\mathrm{L}, \mathrm{M}, \mathrm{H}, \mathrm{VH}$ & $\mathrm{L}, \mathrm{M}, \mathrm{H}, \mathrm{VH}$ & $\mathrm{L}, \mathrm{M}, \mathrm{H}, \mathrm{VH}, \mathrm{UH}$ \\
\hline \multirow{2}{*}{ Ilia } & 4 & 3 & 4 & 4 & 5 \\
\hline & $\mathrm{L}, \mathrm{M}, \mathrm{H}, \mathrm{VH}$ & $\mathrm{L}, \mathrm{M}, \mathrm{H}$ & $\mathrm{L}, \mathrm{M}, \mathrm{H}, \mathrm{VH}$ & $\mathrm{L}, \mathrm{M}, \mathrm{H}, \mathrm{VH}$ & $\mathrm{L}, \mathrm{M}, \mathrm{H}, \mathrm{VH}, \mathrm{UH}$ \\
\hline
\end{tabular}

It should be clarified that in the following table 5, the fuzzy values of the involved features are connected with the Min T-Norm.

Table 5. Fuzzy Rule set (T-Norms Fuzzy-AND) for the determination of the WRI Humidity Air temperature $\quad$ Wind Speed $\quad$ WRI 


\begin{tabular}{|c|c|c|c|}
\hline $\mathrm{H}$ & $\mathrm{L}$ & $\mathrm{M}$ & $\mathrm{L}$ \\
\hline $\mathrm{H}$ & $\mathrm{M}$ & $\mathrm{L}$ & $\mathrm{L}$ \\
\hline $\mathrm{H}$ & $\mathrm{M}$ & $\mathrm{M}$ & $\mathrm{M}$ \\
\hline $\mathrm{H}$ & $\mathrm{M}$ & $\mathrm{H}$ & $\mathrm{M}$ \\
\hline $\mathrm{H}$ & $\mathrm{M}$ & VH & $\mathrm{M}$ \\
\hline $\mathrm{H}$ & $\mathrm{H}$ & $\mathrm{H}$ & $\mathrm{H}$ \\
\hline $\mathrm{H}$ & $\mathrm{H}$ & $\mathrm{VH}$ & $\mathrm{UH}$ \\
\hline M & $\mathrm{L}$ & $\mathrm{L}$ & $\mathrm{L}$ \\
\hline $\mathrm{M}$ & $\mathrm{L}$ & $\mathrm{M}$ & $\mathrm{L}$ \\
\hline M & $\mathrm{L}$ & $\mathrm{H}$ & $\mathrm{L}$ \\
\hline $\mathrm{M}$ & $\mathrm{M}$ & $\mathrm{L}$ & $\mathrm{L}$ \\
\hline M & $\mathrm{M}$ & $\mathrm{M}$ & $\mathrm{M}$ \\
\hline $\mathrm{M}$ & $\mathrm{M}$ & $\mathrm{H}$ & $\mathrm{L}$ \\
\hline $\mathrm{M}$ & $\mathrm{M}$ & VH & $\mathrm{H}$ \\
\hline $\mathrm{M}$ & $\mathrm{M}$ & $\mathrm{UH}$ & $\mathrm{H}$ \\
\hline $\mathrm{M}$ & $\mathrm{H}$ & $\mathrm{L}$ & L \\
\hline M & $\mathrm{H}$ & $\mathrm{M}$ & $\mathrm{M}$ \\
\hline $\mathrm{M}$ & $\mathrm{H}$ & $\mathrm{H}$ & $\mathrm{H}$ \\
\hline $\mathrm{M}$ & $\mathrm{H}$ & $\mathrm{VH}$ & $\mathrm{VH}$ \\
\hline M & $\mathrm{H}$ & $\mathrm{UH}$ & $\mathrm{VH}$ \\
\hline $\mathrm{L}$ & $\mathrm{L}$ & $\mathrm{L}$ & $\mathrm{L}$ \\
\hline $\mathrm{L}$ & $\mathrm{L}$ & $\mathrm{M}$ & $\mathrm{L}$ \\
\hline $\mathrm{L}$ & $\mathrm{L}$ & $\mathrm{H}$ & $\mathrm{L}$ \\
\hline $\mathrm{L}$ & $\mathrm{M}$ & $\mathrm{L}$ & L \\
\hline $\mathrm{L}$ & $\mathrm{M}$ & $\mathrm{M}$ & $\mathrm{L}$ \\
\hline $\mathrm{L}$ & $\mathrm{M}$ & $\mathrm{H}$ & $\mathrm{L}$ \\
\hline $\mathrm{L}$ & $\mathrm{M}$ & $\mathrm{VH}$ & $\mathrm{L}$ \\
\hline $\mathrm{L}$ & $\mathrm{M}$ & $\mathrm{UH}$ & $\mathrm{M}$ \\
\hline $\mathrm{L}$ & $\mathrm{H}$ & $\mathrm{M}$ & L \\
\hline $\mathrm{L}$ & $\mathrm{H}$ & $\mathrm{H}$ & $\mathrm{L}$ \\
\hline
\end{tabular}

Table 6. Number of rules in the fuzzy rule sets use for the determination of each CRI and for the UORI for each area.

\begin{tabular}{llllll}
\hline & WRI & DRI & TRI & VRI & UORI \\
\hline Kefalonia & 23 & 8 & 44 & 20 & 46 \\
Chania & 23 & 11 & 50 & 18 & 61 \\
Ilia & 33 & 12 & 47 & 21 & 68 \\
\hline
\end{tabular}

5. Each of the four CRIs has been calculated. The output of the Sugeno-type FIS takes values in the closed interval $[0,1]$.

6 . The UORI has been produced by adjustment of the weights of the fuzzy rules.

Table 7. Four CRIs and UORI membership functions

\begin{tabular}{cc}
\hline Linguistics of CRIs and UORI & Constant Values \\
\hline Low & 0 \\
Medium & 0.5 \\
High & 0.9 \\
Very High & 0.95 \\
Ultra High & 1 \\
\hline
\end{tabular}

7. The actual burned area for each area under study has been fuzzified by obtaining four fuzzy Linguistics representing the Actually Burned Surfaces (ACBUSij) $i=1 \ldots 4$ and $\mathrm{j}=1 \ldots \mathrm{N}$ ( $\mathrm{N}$ is the number of examined cases) namely: Low Burned (LBUR), Average Burned (ABUR), High Burned (HBUR) and Extremely Burned (ExBUR). 
Subsequently, a comparative analysis has been performed between the four CRIs and the UORI with the ACBUS for each case.

Table 8. ACBUS is a two dimensional Matrix as it is shown below. $\mathrm{N}$ is the number of the areas under study

\begin{tabular}{llll}
\hline$\mu_{11}=\mathrm{LBUR}_{11}$ & $\mu_{12}=\mathrm{ABUR}_{12}$ & $\mu_{13}=\mathrm{HBUR}_{13}$ & $\mu_{14}=\mathrm{ExBUR}_{14}$ \\
\hline$\mu_{21}=\mathrm{LBUR}_{21}$ & $\mu_{22}=\mathrm{ABUR}_{22}$ & $\mu_{23}=\mathrm{HBUR}_{23}$ & $\mu_{24}=\mathrm{ExBUR}_{24}$ \\
$\ldots$. & $\ldots \ldots$ & $\ldots \ldots$ & $\ldots .$. \\
$\mu_{\mathrm{N} 1}=\mathrm{LBUR}_{\mathrm{N} 1}$ & $\mu_{\mathrm{N} 2}=\mathrm{ABUR}_{\mathrm{N} 2}$ & $\mu_{\mathrm{N} 3}=\mathrm{HBUR}_{\mathrm{N} 3}$ & $\mu_{\mathrm{N} 4}=\mathrm{ExBUR}_{\mathrm{N} 4}$ \\
\hline
\end{tabular}

8. The fuzzy T/Norms (Algebraic, Drastic, Einstein, Hamacher - products, Min relation) have been applied through the combination of all four (4) ACBUS membership values (in pairs) in order to perform three distinct risk scenarios.

Totally six Pair Risk Indices (PARI) have been developed by considering the partial indices in pairs.

a. Conjunction between the:

i) Meteorological Indices (MI) AND the Drought indices (DRI) which produces the (MIDRI)

ii) The Topographic indices (TI) AND the Vegetation indices (VEGI) that produces the (TIVEGI). Thus, two Pair Risk Indices (PARI) have been developed namely: the MIDRI and the TIVEGI.

b. Conjunction between the:

i) $\quad$ MI AND the TI which produces the (MITI)

ii) The DRI AND the VEGI which produces the (DRIVEGI). Also two Pair Risk Indices have been developed the MITI and the DRIVEGI.

c. Conjunction between the:

i) $\quad$ MI AND the VEGI which produces the (MIVEGI)

ii) DRI AND the TI that produces the (DRITI) . Moreover two Pair Risk Indices have been designed MIVEGI and DRITI.

Totally for each research area 5 (the number of T-Norms)*6 (the number of PARI) $=30$ cases were obtained.

9. Use of the Chi-Square Statistical Test at significance level of $a=0.05$ in order to obtain the PARI where the three Linguistics (low, medium, high risk) are depended on the three corresponding linguistics (low, medium, high Burned) of the ACBUS. The tables used were $3 * 3$ and the degrees of freedom $\mathrm{df}_{4}=9,488$. 


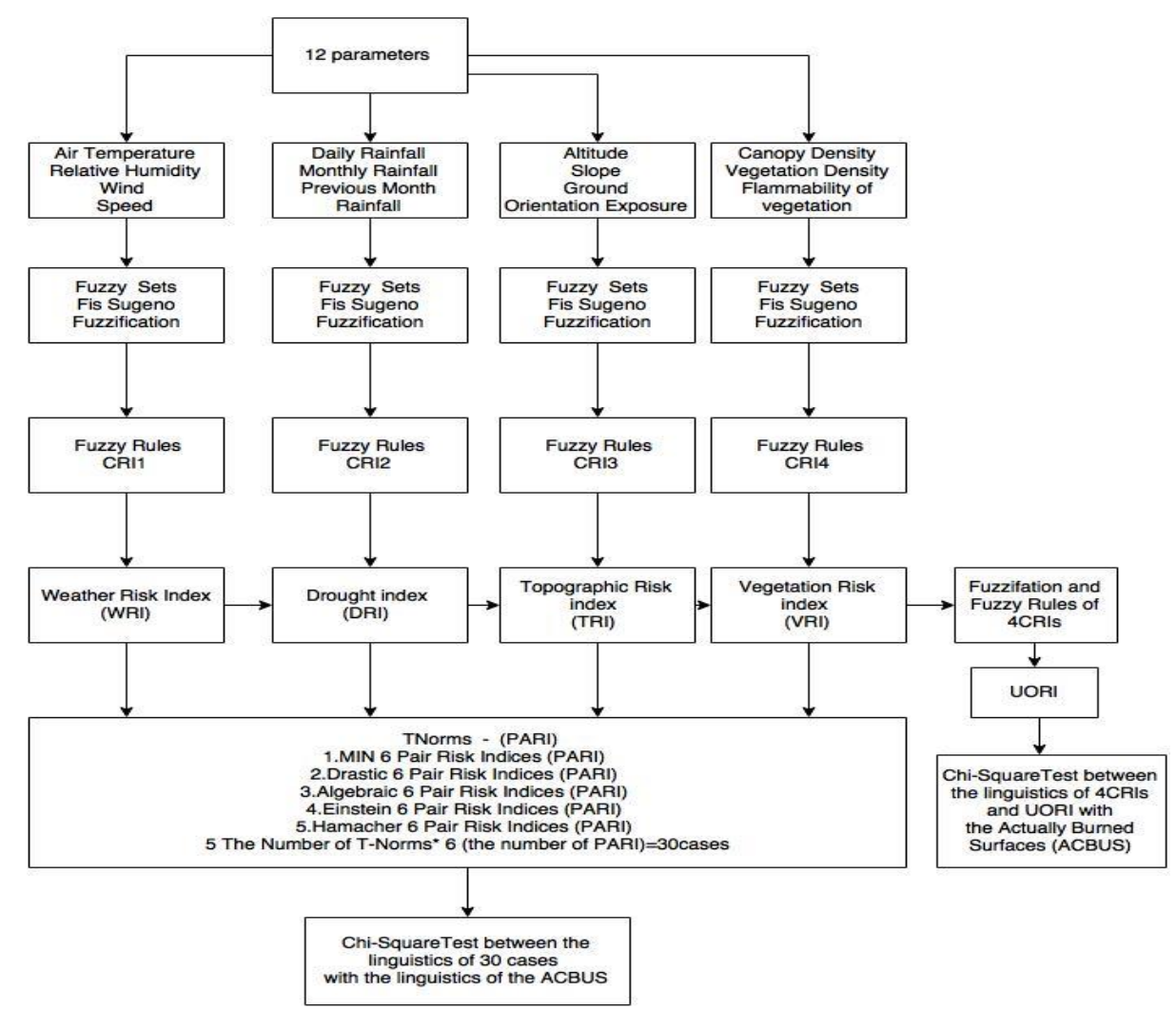

Figure 1. Flowchart of the proposed methodology

\section{Results and Discussion}

After extensive testing on multiple scenarios and different methods for the examination of all possible coupling combinations of forest fire severity for Sites Kefallonia Chania and Ilia, important conclusions were drawn on what indicators determine the risk of burned areas. The best Linguistic fitting with the ACBUS indices was derived from the UORI and from the combination of MI-TI PARI for all areas. The DRI and other combinations like the DRIVEGI did not show high convergence with the actual burned areas.

Table 9. Test Statistic and P-Value between four CRIs and UORI with ACBUS

\begin{tabular}{llllll}
\hline T-Norms & MI- ACBUS & DRI- ACBUS & TI- ACBUS & VEGI- ACBUS & UORI- ACBUS \\
\hline Ileia & & & & & \\
Test Statistic & 27.58 & 0.82 & 31.37 & 15.45 & 180.18 \\
P-Value & 0.00001 & 0.9344 & 0.00001 & 0.0038 & 0.00001 \\
Kefalonia & & & & & \\
Test Statistic & 105.22 & 0.316 & 1.4 & 3.34 & 716.04 \\
P-Value & 0.00001 & 0.988 & 0.843 & 0.5 & 0.00001 \\
Chania & & & & &
\end{tabular}




\begin{tabular}{llllll} 
Test Statistic & 42.45 & 0.68 & 67.67 & 7.76 & 258.07 \\
P-Value & 0.00001 & 0.9531 & 0.00001 & 0.1 & 0.00001 \\
\hline
\end{tabular}

For the Ilia prefecture, the MI and the TI and all of their combinations have shown an important influence on the actual burned areas. According to the $\mathrm{X}$ squared test the null hypothesis was rejected which has proved the dependency. Moreover, the DRIVEGI and the MIVEGI indices have shown a rather minor effect on the determination of the actual burned areas (small Test Statistic-higher P-Value). On the other hand, the burned area has proven to be independent from the MIDRI PARI.

In Kefalonia the MI index and all of its combinations have proved to have great influence in the burned areas. The result was the opposite for the other indices (TI, VEGI,DRI).

In Chania, the TI and MI indices and all of their combinations have shown a high correlation with the total burned areas (high Test Statistic values and Low P-Value). The DRIVEGI does not seem to be correlated to the burned areas.

Table 10. P-Values between the Linguistics of the PARI and the Linguistics of the ACBUS

\begin{tabular}{cllllll}
\hline T-Norms & MIDRI & TIVEGI & MITI & DRIVEGI & MIVEGI & DRITI \\
\hline Ileia & & & & & & \\
MIN & 0.33 & 0.00001 & 0.00001 & 0.004 & 0.01 & 0.00001 \\
Algebraic & 0.29 & 0.00001 & 0.00001 & 0.004 & 0.0029 & 0.00001 \\
Drastic & 0.51 & 0.00001 & 0.00001 & 0.02 & 0.01 & 0.00001 \\
Einstein & 0.289 & 0.00001 & 0.00001 & 0.0018 & 0.012 & 0.00001 \\
Hamacher & 0.33 & 0.00001 & 0.00001 & 0.004 & 0.011 & 0.00001 \\
Kefalonia & & & & & & 0.005 \\
MIN & 0.00001 & 0.63 & 0.00001 & 0.50 & 0.00001 & 0.84 \\
Algebraic & 0.00001 & 0.52 & 0.00001 & 0.49 & 0.00001 & 0.78 \\
Drastic & 0.00001 & 0.83 & 0.00001 & 0.55 & 0.00001 & 0.84 \\
Einstein & 0.00001 & 0.93 & 0.00001 & 0.47 & 0.00001 & 0.84 \\
Hamacher & 0.00001 & 0.61 & 0.00001 & 0.50 & & \\
Chania & & & & & 0.00001 & 0.00001 \\
MIN & 0.00001 & 0.00001 & 0.00001 & 0.10 & 0.47 & 0.37 \\
Algebraic & 0.00001 & 0.00001 & 0.00001 & 0.09 & 0.00001 & 0.00001 \\
Drastic & 0.00001 & 0.00001 & 0.00001 & 0.09 & 0.00001 & 0.00001 \\
Einstein & 0.00001 & 0.00001 & 0.00001 & 0.09 & 0.00001 & 0.00001 \\
Hamacher & 0.00001 & 0.00001 & 0.00001 & 0.10 & & \\
\hline
\end{tabular}

Table 11. Test Statistic between the Linguistics of the PARI and the Linguistics of the ACBUS.

\begin{tabular}{cllllll}
\hline T-Norms & MIDRI & TIVEGI & MITI & DRIVEGI & MIVEGI & DRITI \\
\hline Ileia & & & & & & \\
MIN & 4.6 & 59.06 & 291.5 & 15.01 & 12.55 & 35.6 \\
Algebraic & 4.91 & 265.12 & 484.55 & 15.05 & 16.05 & 40.67 \\
Drastic & 3.28 & 67.51 & 475.69 & 11.57 & 13.18 & 33.78 \\
Einstein & 4.97 & 35.82 & 468.27 & 11.88 & 12.8 & 40.97 \\
Hamacher & 4.6 & 60.78 & 329.19 & 15.01 & 12.97 & 41.58 \\
Kefalonia & & & & & & \\
MIN & 71.89 & 2.57 & 646.13 & 3.33 & 14.55 & 1.4 \\
Algebraic & 71.93 & 3.19 & 646.62 & 3.39 & 215.76 & 1.4 \\
Drastic & 59.04 & 1.45 & 646.53 & 3.02 & 323.87 & 1.72 \\
Einstein & 78.19 & 0.79 & 649.64 & 3.53 & 215.81 & 1.4 \\
Hamacher & 78.15 & 2.65 & 646.28 & 3.3 & 217.39 & 1.4 \\
Chania & & & & & & \\
MIN & 45.62 & 49.63 & 153.57 & 7.68 & 38.55 & 66.85
\end{tabular}




\begin{tabular}{cllllll} 
Algebraic & 42.46 & 54.67 & 124.43 & 7.87 & 3.5 & 4.25 \\
Drastic & 42.98 & 39.86 & 113.23 & 7.87 & 34.88 & 70.65 \\
Einstein & 43.5 & 55.01 & 113.38 & 7.87 & 39.48 & 67.88 \\
Hamacher & 42.46 & 33.25 & 118.89 & 7.7 & 41.35 & 66.98 \\
\hline
\end{tabular}

Summarizing and evaluating the four indicators studied it was proved that the MI and the TI are the key factors that affect the severity of forest fires whereas beyond any expectation the DRI was not the catalyst or retarding factor in the spread of forest fires. Also from the examined pairs of indices, the combination of MI-TI has shown the highest test Statistic and the highest correlation with the ACBUS index.

Finally, it was observed that the fuzzy T-NORMS relations, constitute a highly reliable method for the development of a unified overall risk index (UORI) which is capable of modeling a very complex problem by combining several parameters or partial indices.

\section{Conclusions-Future Work}

This research proposes the use of an innovative method for the analysis and study of the main parameters related to forest fires. The proposed approach was developed towards the estimation of the UORI (forest fire severity index) which is based on advanced soft computing techniques. More specifically, a fuzzy inference system was developed. After the performance of extensive testing, the actual interrelationships between the involved parameters were discovered and hidden knowledge was revealed. This modeling research effort has yielded high rates of accurate classifications as a result of a comparative analysis between the obtained indices and the ACBUS. The function of the model was tested in consideration with various scenarios and presented important outcome regarding those indices or their pairs which directly determine the forest fires risk.

It is important to mention that it is the first time that so many parameters are used and combined to estimate the potential severity of wildfires, creating numerous individual indicators in order to construct a unified index that highly reflects the ACBUS.

As future directions that could improve the proposed model we suggest the potential use of more parameters directly related to forest fires in order to create more combinations of fuzzy rules and sub-indicators. In this way it will be possible to derive an even stronger final adaptive unified index compatible with the ACBUS.

Finally, we propose the future use of other machine learning methods (unsupervised competitive learning) or hybrid soft computing approaches (fuzzy-neural networks) and optimization algorithms aimed at even higher rates of correct classification.

\section{References}

[1] Aldrich, S.R., Lafon, C.W., Grissino-Mayer H.D., DeWeese G.G., Fire history and its relations with land use and climate over three centuries in the central Appalachian Mountains, USA, Journal of Biogeography, Vol.41, pp. 2093-2104 (2014). 
[2] Anezakis, B., Iliadis, L., Estimation of fire ignition and fire spread risk indices with fuzzy conjunction models MAX-MIN and MAX-PROD, Environmental Policy: Theory and Practice. Published by the Democritus University of Thrace, pp.20-32, (in Greek), (2015).

http://utopia.duth.gr/ emanolas/files/Dervitsiotis.pdf

[3] Bougoudis, I., Dermetzis, K., Iliadis, L., HISYCOL A hybrid computational intelligence system for combined machine learning: the case of air pollution modeling in Athens, Journal of Neural Computing and Applications, pp.1-16, Springer, (2015).

[4] Bougoudis, I., Dermetzis, K., Iliadis, L., Fast and low cost prediction of extreme air pollution values with hybrid unsupervised learning, Journal of Integrated Computer-Aided Engineering, vol. Preprint, no. Preprint, pp. 1-13, (2015).

[5] Calvo T., Mayor G., Mesira R., Aggregation Operators: New Trends and Applications. Studies in Fuzziness and Soft Computing, Physica-Verlag, Heidelberg, (2002).

[6] Catry, F.X., Rego, F.C., Moreira, F., Bacao, F., Characterizing and modelling the spatial patterns of wildfire ignitions in Portugal: fire initiation and resulting burned area Modelling, Monitoring and Management of Forest Fires I, WIT Transactions on Ecology and the Environment, Vol. 119, pp. 213-221, (2008).

[7] Cox E., Fuzzy Modeling and Genetic Algorithms for Data Mining and Exploration Elsevier Science, USA, (2005).

[8] Huang C.E., Ruan D., Kerre E., Fuzzy Risks and Updating a Fuzzy Risk with New Observations, Journal risk analysis an international journal In Press, (2007).

[9] Iliadis, L., Betsidou, T. Soft Computing modeling of wild fire Risk Indices: the risk profile of Peloponnesus region in Greece: E-Agriculture and Rural Development: Global Innovations and Future Prospects, IGI Global Publishers of Science and Technology Pennsylvania, New York, USA Publisher Professor Maumbe, B.M., Davis College of Agriculture, Natural Resources and Design, W. Virginia University, USA, pp.220-234, (2012).

[10] Iliadis, L., Skopianos, S., Tachos, S., Spartalis, S., A Fuzzy Inference System Using Gaussian Distribution Curves for Forest Fire Risk Estimation Proceedings 6th AIAI, (International Conference of Artificial Intelligence Applications and Innovations) Springer LNCS (Lecture Notes in Computer Science) IFIP AICT 339, pp. 376-386, (2010).

[11] Iliadis, L., Zigkrika, N. Evaluating fuzzy multi-feature scenarios for forest fire risk estimation Journal of Information Technology in Agriculture, Vol. 4, (2011).

[12] Kailidis, D., Forest Fires, 3rd edition, Giahoudi-Giapouli editions, Thessaloniki, Greece, pp.510, (in Greek), (1990).

[13] Kecman V., Learning and Soft Computing, MIT Press, London England, (2001).

[14] Leondes C., Fuzzy logic and Expert Systems Applications. Academic Press, USA, (1998).

[15] Nguyen H., Walker E., A first Course in Fuzzy Logic, Chapman and Hall, USA, (2000).

[16] Özbayoğlu, A.M., Bozer, R., Estimation of the Burned Area in Forest Fires Using Computational Intelligence Techniques, Complex Adaptive Systems, Procedia Computer Science, Vol.12, pp.282-287, (2012).

[17] Papakonstantinou, X., Iliadis, L., Pimenidis, E., Maris, F. Fuzzy Modeling of the Climate Change Effect to Drought and to Wild Fires in Cyprus Proceedings ISQLIS Workshop Corfu (Information Systems for Quality of Life Information Services) Springer LNCS (Lecture Notes in Computer Science) IFIP AICT 363, Vol.1, pp. 516-528, (2011).

[18] Shidik, G.F., Mustofa, K., Predicting Size of Forest Fire Using Hybrid Model Information and Communication Technology, Vol.8407, Lecture Notes in Computer Science, pp.316-327, (2014).

[19] Sugeno, M., Industrial Applications of Fuzzy Control, Elsevier Science publishing company, (1985)

[20] http://www.actuar.aegean.gr/notes/22-Katsanos-Avouris.pdf (in Greek) 